\title{
Urdimento
}

Revista de Estudos em Artes Cênicas

E-ISSN: 2358.6958

\section{Outros territórios: relato de uma experiência teatral em penitenciárias femininas}

\author{
Fernanda de Lannoy Stürmer \\ Luzia Ainhoren Meimes \\ Nathalia Scapin Barp \\ Rodrigo Azevedo de Lima \\ Tatiana Cardoso da Silva
}

\section{Para citar este artigo:}

STÜRMER, Fernanda de Lannoy; MEIMES, Luzia Ainhoren; BARP, Nathalia Scapin; LIMA, Rodrigo Azevedo de; SILVA, Tatiana Cardoso da. Outros territórios: relato de uma experiência teatral em penitenciárias femininas. Urdimento, Florianópolis, v. 3, n. 39, nov./dez. 2020. 


\title{
Outros territórios:
}

Relato de uma experiência teatral em penitenciárias femininas

\author{
Fernanda de Lannoy Stürmer \\ Luzia Ainhoren Meimes ${ }^{2}$ \\ Nathalia Scapin Barp ${ }^{3}$ \\ Rodrigo Azevedo de Lima ${ }^{4}$ \\ Tatiana Cardoso da Silva ${ }^{5}$
}

\begin{abstract}
Resumo
Este texto é um relato de experiência sobre a ação de extensão universitária nomeada "Tempo de impermanência: teatro em penitenciárias femininas do Rio Grande do Sul", desenvolvida em 2018 por professora e estudantes do curso Graduação em Teatro: Licenciatura, da Universidade Estadual do Rio Grande do Sul na Penitenciária Modulada de Montenegro e no Presídio Estadual Feminino de Torres. A ação contou com apresentações do espetáculo O jardim das cerejeiras, debates, oficinas teatrais e outras atividades junto às mulheres privadas de liberdade. A partir de referenciais do Teatro, da Filosofia e das Ciências Humanas, são feitas reflexões sobre o impacto de ações teatrais no cárcere.
\end{abstract}

Palavras-chave: Teatro. Prisão. Educação. Mulheres em privação de liberdade. Território.

\footnotetext{
${ }^{1}$ Atriz e professora. É formada na Graduação em Teatro: Licenciatura pela UERGS e em Licenciatura em História pela UFRGS. É analista em assuntos culturais na Secretaria de Estado da Cultura do RS, atuando no Núcleo de Teatros da Casa de Cultura Mario Quintana em Porto Alegre. nandasturmer@gmail.com

${ }^{2}$ Atriz e professora de teatro. Graduada no curso Graduação em Teatro: Licenciatura pela UERGS. Mestranda no Programa de Pós Graduação em Artes da Cena, UNICAMP. Integrante do grupo Balalaica e da TrupeZonaDeTeatro. Luzia.ainhoren.meimes@gmail.com

${ }^{3}$ Atriz-pesquisadora e professora de teatro. Graduada em Teatro: Licenciatura pela UERGS. Colaboradora dos Grupos de Pesquisa GESTA (RS) e MOTIM (RJ). Integrante dos grupos Balalaica e Treta Teatro. nathaliabarp1410@gmail.com

${ }^{4}$ Ator, diretor e professor de teatro. Graduado em Teatro: Licenciatura pela UERGS. Professor de Artes/RS e professor de teatro da APAE João de Barro/RS. rodrigoazvedo@hotmail.com

${ }^{5}$ Doutora e Mestre em Artes Cênicas pela UFRGS. Professora do curso Graduação em Teatro: Licenciatura, da UERGS. Diretora e atriz. Líder do grupo de pesquisa GESTA. tatianacardoso8@gmail.com
} 
Other domains:

Report of a theatrical experience in female prisons

\begin{abstract}
This article serves as a report and reflection on the university community engagement program Time of impermanence: theater in female prisons in Rio Grande do Sul, which was developed in 2018 at the Montenegro Modulated Penitentiary and the Torres Female State Prison by the theatre teacher training course at the Universidade Estadual do Rio Grande do Sul. Using references from theater, philosophy, and the social sciences and analyzing the notion of space, we reflect on the impact of theater in prison. The project consisted of presentations from the play The Cherry Orchard, discussions, theatrical workshops and other activities with incarcerated women.
\end{abstract}

Keywords: Theater. Prison. Education. Women deprived of liberty. Domains.

Otros territorios:

Relato de una experiencia teatral en prisiones femeninas

\title{
Resumen
}

Este texto es un relato de experiencia de actividad de extensión universitaria nombrada "Tempo de Impermanência: teatro em penitenciárias femininas do Rio Grande do Sul". Experiencia desarrollada en el 2018 por profesora y alumnos del Curso de Grado en Teatro, Licenciatura de la Universidad Estadual do Rio Grande do Sul en la Penitenciaria Modulada de Montenegro y en el Presidio Estadual Femenino de Torres. La actividad consistió en presentaciones del espectáculo O jardim das cerejeiras, debates, oficinas teatrales y otras actividades propuestas a las mujeres privadas de libertad. A partir de referenciales del Teatro, de la Filosofía y de las Ciencias Humanas, se reflexionó sobre el impacto de actividades teatrales realizadas en la cárcel.

Palabras-llave: Teatro. Prisión. Educación. Mujeres privadas de libertad. Territorio. 
Duas carruagens são ouvidas dirigindo-se para a casa. [...]

O barulho fora do palco fica cada vez maior. Uma voz é ouvida: "Vamos entrar ali."

Neste relato, seguimos os rastros de uma história vivida coletivamente e apertamos os corações com força para resgatarmos as percepções e pensamentos que nos atravessaram enquanto grupo de teatro universitário que atuou no cárcere. Retomamos os passos cravados sob piso frio, grama e cimento, quando realizamos, em 2018, a ação de extensão universitária Tempo de impermanência: teatro em penitenciárias femininas do Rio Grande do Sul, por meio do Edital Proext/MEC, 2015. A ação aconteceu na Penitenciária Modulada de Montenegro, no seu anexo feminino, atualmente desativado, e no Presídio Estadual Feminino de Torres?. Teve como principais objetivos: realizar apresentações do espetáculo O jardim das cerejeiras; promover debates e oficinas teatrais para as apenadas; e produzir a criação e apresentação pública de materiais cênicos, ou seja, pequenas cenas teatrais criadas com as mulheres em situação de cárcere. Este relato de experiência é feito pelo mesmo grupo ${ }^{8}$ que propôs a ação extensiva, composto pela professora responsável e os estudantes do curso Graduação em Teatro: Licenciatura da Universidade Estadual do Rio Grande do Sul (UERGS), com sede na cidade de Montenegro?

Implacável é a união entre tempo e espaço, que nos lança impiedosamente para outros planos no momento em que nossa visão já se acostumava com uma lembrança. Ainda assim, o tecido da memória é urgente e mutável, são restos que

\footnotetext{
${ }^{6}$ Tchekhov, 2013, p. 3.
}

${ }^{7}$ As duas penitenciárias foram eleitas para as ações do projeto por abrigarem mulheres e por fazerem parte da 1 a Delegacia Regional, situadas dentro do estado do Rio Grande do Sul.

${ }^{8}$ Coordenadora do projeto: Tatiana Cardoso da Silva. Participantes: Camila Pasa, Eduardo Hass, Fernanda Stürmer, Luzia Ainhoren, Mateus Frena, Nathalia Barp, Rafaela Giacomelli, Rodrigo Azevedo e Rodrigo Waschburger.

${ }^{9}$ Os cursos de licenciatura em Teatro, Artes Visuais, Dança e Música da Universidade Estadual do Rio Grande do Sul (UERGS) funcionam no mesmo espaço físico, na cidade de Montenegro, região metropolitana de Porto Alegre, RS. 
se articulam querendo desenhar ainda mais um esboço diferente.

Então, depois de percorrido certo tempo, reunimo-nos com o objetivo de resgatarmos os principais passos do projeto e refletirmos sobre as seguintes perguntas: que sentidos nossa passagem pelo ambiente prisional promoveu em nossa formação e atuação em teatro? Como percebemos a reação daquelas mulheres em situação de privação de liberdade às nossas propostas artísticas e educacionais? É possível identificar o impacto que nossa ação teve naquele ambiente e naquelas mulheres? Que impactos elas provocaram em nós?

Para pensarmos sobre essas questões, consideramos aquele encontro não apenas como algo ocorrido em um tempo e espaço específicos, mas como a instauração de um território próprio, criado no momento em que nossa experiência acontecia, ou seja, no momento do encontro entre nós e aquelas mulheres privadas de liberdade. Pensamos a noção de território próxima do que afirma Guelman (apud Plácido e Santos, 2019, p. 158): "os territórios não são somente dimensões físicas, mas expressões de memória, de pertencimento e de gênero [...]”. Reconhecemos que um território próprio fez-se enquanto movimento de forças que se confrontavam, se agitavam, se complementavam e se rearticulavam na instauração do acontecimento teatral proposto nas penitenciárias. Na relação entre as pessoas da universidade, as detentas, as assistentes sociais, o pessoal de apoio e os dirigentes, criou-se um território de passagem, de trânsito, de abertura à rearticulação de valores estéticos e sensíveis que, ao nosso ver, fomentaram novas subjetividades e novos pontos de vista naqueles e naquelas que participaram do evento. Esse território sensível confrontava-se diretamente com outro, o da cadeia, onde as relações de poder e punição configuram instituições de controle historicamente estabelecidas.

Nossa escrita-memória vagueia pelos caminhos percorridos desde o primeiro contato com uma das penitenciárias, encontro que abriu as portas para a idealização e para a produção do projeto "Tempo de Impermanência". Rememoramos como se deram as ações propostas no projeto e apresentamos alguns dados sobre a realidade enfrentada pelas mulheres encarceradas dentro do sistema prisional brasileiro. Refletimos sobre o trânsito e as passagens entre 
os territórios do teatro e da prisão e questionamos, mais uma vez, a obsolescência do sistema carcerário e a importância e o papel da arte ao atuar em espaços como esse. Para descrever e pensar sobre aquela experiência, além dos teóricos do Teatro, nos aproximamos de autores de outras áreas, como Geografia, Filosofia e Sociologia.

\section{Primeiro contato}

O medo de não sermos compreendidos. E o medo ainda mais paralisante de sermos compreendidos ${ }^{10}$.

Em 2013, a equipe de assistentes sociais da Penitenciária Modulada de Montenegro contatou os professores dos cursos de Artes da UERGS a fim de desenvolver atividades culturais no presídio. Nosso grupo participava do projeto de pesquisa "Ação psicofísica: o ator no universo tchekhoviano", que tinha como mote para o trabalho de atuação os ensinamentos de Stanislavski e Grotowski, utilizados para a criação do espetáculo 0 jardim das cerejeiras ${ }^{11}$ de Anton Tchekhov. Aceitamos o desafio de apresentar nossa versão da obra de Tchekhov para aquelas mulheres em condição de privação de liberdade.

Para conhecermos o contexto e definirmos o local da apresentação, fizemos uma primeira visita à penitenciária de Montenegro. Desde então, deparamo-nos com a difícil realidade daquelas mulheres. Muitas delas estavam aprisionadas sem receber apoio familiar, especialmente de seus companheiros, situação contrastante à realidade dos homens encarcerados, que, em sua maior parte, recebem visitas e apoio de suas companheiras. Angela Davis (2019) aponta uma diferenciação que agrava ainda mais a situação das mulheres encarceradas:

\footnotetext{
10 Trecho do prólogo do roteiro do espetáculo o jardim das cerejeiras, que consiste em uma adaptação da obra de Anton Tchekhov, em que há um prólogo escrito pelos atores do grupo.

${ }^{11}$ Direção: Tatiana Cardoso da Silva. Elenco: Camila Pasa, Fernanda Stürmer, Luzia Ainhoren, Nathalia Barp, Rodrigo Azevedo. Este espetáculo foi criado em 2012 durante uma das disciplinas do curso Graduação em Teatro: Licenciatura, denominada Oficina Montagem II. Posteriormente, o mesmo grupo desenvolveu um projeto de pesquisa e extensão, nos anos de 2013 e 2014 respectivamente. Neste período, também fizeram parte do elenco: Carlos Mödinger, Igor Simões, Morgana Rodrigues, Lis Machado, Diewerson Nascimento, Gil Collares, Daniela Guerrieri, Raquel Zepka e Marcelo Carvalho.
} 
A criminalidade masculina [...] sempre foi considerada mais "normal" do que a criminalidade feminina. Sempre houve uma tendência a encarar as mulheres que foram punidas publicamente pelo Estado por seu mau comportamento como significativamente mais anormais e muito mais ameaçadoras para a sociedade do que suas numerosas contrapartes masculinas. (Davis, 2019, p. 71).

A situação de abandono da mulher presa fica evidente, também, pelos entraves burocráticos da justiça e do sistema carcerário, que muitas vezes não comportam a progressão das apenadas para o regime semiaberto, fazendo com que muitas delas permaneçam em regime fechado por mais tempo do que a pena determina. Soma-se a isso o fato de que esse é um sistema calcado em uma organização predominantemente masculina, que não prevê, por exemplo, as especificidades do corpo feminino. É comum encontrar mulheres em espaços prisionais pelo Brasil com caroços na mama e no útero, sem assistência médica adequada, bem como sem acesso a absorventes higiênicos, cabendo às detentas o improviso com panos ou, até mesmo, miolo de pão.

Assim, fica evidente que, mesmo considerando a importância do tema geral, é necessário que se discuta e se torne visíveis, também, os graves problemas que mulheres encarceradas enfrentam. Além disso, a população carcerária feminina é mundialmente crescente, como aponta Davis (2019).

Especificamente sobre a realidade brasileira, é importante ressaltar que

[...] o encarceramento de mulheres vem ganhando grande visibilidade em razão da crescente população carcerária feminina: de acordo com o Infopen Mulheres 2018, em junho de 2016, o país contava com 42,3 mil presas, compondo uma taxa de aumento de 455\% entre os anos de 2000 e 2016. Além disso, dentre os países que mais aprisionam mulheres no mundo, o Brasil ocupa a 4a posição, ficando atrás apenas dos Estados Unidos, da China e da Rússia." (Sigilló, 2018, p.01).

Ao conhecer mais de perto a realidade dentro da prisão naquele primeiro encontro, duvidamos um pouco sobre a validade de apresentarmos o jardim das cerejeiras. A priori, é difícil imaginar muitas relações possíveis de estabelecer entre um texto clássico, contextualizado na Rússia do final do século XIX, e o espaço de 
um cárcere brasileiro, gélido, entre muros, cheio de grades, com agentes penitenciários armados e mulheres uniformizadas e disciplinadas. Que relações poderiam existir entre o drama da decadente família aristocrática russa, de 0 jardim das cerejeiras, e o público da penitenciária? A apresentação feita em 2013 foi um ensaio do que viemos a sentir depois, em relação ao todo do projeto que executamos em 2018. Ela serviu para compreender que o que uniu o mundo de Tchekhov - ou do teatro - e o cárcere foi o compartilhamento de um tema comum: a fragilidade da condição humana e a contínua perplexidade diante da vida.

Figura 1 - Sororidade. Colagem manual de Luzia Ainhoren, a partir de fotografias de Rodrigo Waschburger, ambos participantes do projeto. Feita com papel, cola e oil pastel.

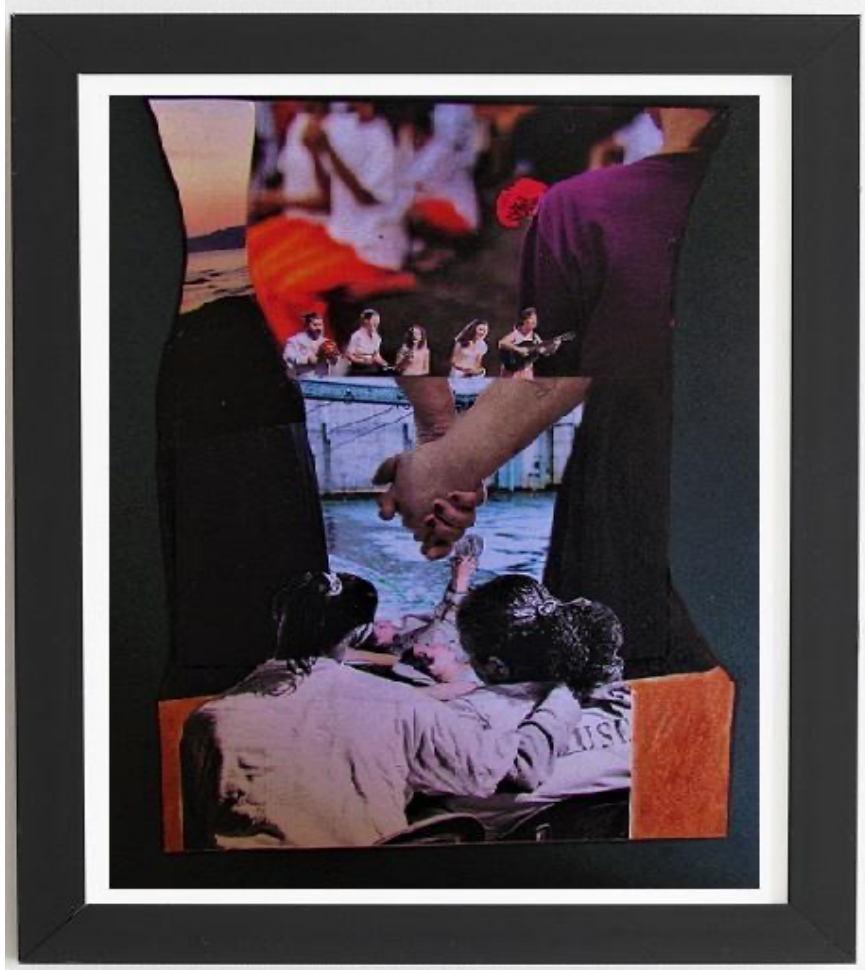

De outra parte, conhecer as mulheres, conversar com elas e com as assistentes sociais após o espetáculo reafirmou nossos propósitos estéticos e artísticos ao desejarmos compor com Tchekhov. Foi através da reação das apenadas em determinadas falas dos personagens que conseguimos reconhecer nuances ainda não percebidas no texto, mesmo depois de um ano de ensaios e 
apresentações dentro do contexto acadêmico. Foi naquela apresentação no presídio, também, que percebemos melhor o tom cômico da obra, já que o riso das detentas ecoou diante das contradições tão humanas das personagens. Como foi o caso com a personagem da empregada, Duniacha, que acredita ser como uma dama; ou diante do patrão, Gaiev, homem em torno dos cinquenta anos, que ainda precisa ser cuidado como uma criança pelo velho criado, Firs.

Mesmo inseridas em realidades sociais completamente diferentes - e aí está a genialidade de um texto dramático clássico como esse de Tchekhov - ao assistirem ao espetáculo, as detentas encontraram ecos de suas próprias trajetórias na história da personagem Liuba, que perdeu um filho aos sete anos de idade, foi abandonada pelo marido e que, no tempo da peça, está prestes a perder a casa onde viveu por toda sua vida. Reverberava na audiência a comoção pelas dificuldades das personagens, a iminente despedida da casa, a necessidade de se afastarem do lugar de afeto e de memória. Ainda, o silêncio subjacente que permeia os diálogos ao longo da peça mostrava cada personagem em seu próprio mundo, quase indiferentes às falas uns dos outros, revelando a sua profunda solidão.

Não sabemos dizer ao certo que sentidos esse acontecimento despertou naquelas mulheres. No entanto, recebemos olhares curiosos, generosos e melancólicos. Escutamos risos, choros e cochichos. Conversamos, trocamos impressões e ideias, elas nos elogiaram pela apresentação do teatro, e nós as enaltecemos por sua coragem em resistir ao cárcere. Fez-se o encontro entre "o pessoal do teatro" e o público. O contato instaurou-se no pátio, e uma atmosfera de cumplicidade reverberou pelos corredores da cadeia: a semente estava plantada.

Saímos com a sensação de que nossas ideias, antes tão limitadas, sobre o presídio, foram implodidas nesse encontro. Naquela realidade específica, mesmo que por alguns instantes, a função ideológica do presídio como "um local abstrato no qual os indesejáveis são depositados" (Davis, 2019, p.16) diluiu-se diante de nossos olhos. Obviamente que, em termos macroscópicos, a função ideológica da prisão permanecia e, infelizmente, ainda permanece. De certa forma: "ela nos livra 
da responsabilidade de nos envolver seriamente com os problemas de nossa sociedade, especialmente aqueles produzidos pelo racismo e, cada vez mais, pelo capitalismo global” (Davis, 2019, p. 17). Mas, em termos microscópicos, elevaramse as trocas humanas e subjetivas entre pessoas repletas de sentimentos e contradições. Relacionamo-nos e criamos um momento de reflexão, conhecimento e emoção, independente de nossas condições de proveniência.

Foi a partir dessa experiência, tão marcante para nós como artistas e acadêmicos, realizada em 2013, que resolvemos aprofundar o encontro entre universidade e prisão, através de um projeto de extensão universitária contemplando não só a Penitenciária Modulada de Montenegro, mas também o Presídio Estadual Feminino de Torres, ambas instituições pertencentes a mesma coordenadoria regional. O projeto foi aprovado em 2015 pelo edital ProEx/MEC e, por conta de alguns entraves burocráticos, foi executado apenas em 2018.

\section{Tempo de impermanência: um caminho para a prática}

Não é ninguém. Eu jurei que era. Foi uma visão. Ali, à direita, no caminho da cabana, aquela árvore branca, toda curvada... Não é uma mulher? ${ }^{12}$

Recordamos o calor do sol na recepção da penitenciária, que contrastava com os corredores pouco iluminados do prédio, no primeiro dia do projeto "Tempo de impermanência: teatro em penitenciárias femininas do Rio Grande do Sul”, ação extensiva dentro da prisão, que consistia em apresentações do espetáculo 0 jardim das cerejeiras, baseado na obra de Anton Tchekhov, bem como debates sobre nosso processo de criação e oficinas teatrais dirigidas às mulheres em situação de cárcere. Ao término das oficinas, as apenadas criaram um material cênico, que foi levado ao público dentro das próprias penitenciárias.

O território prisional possui suas regras, que regem não somente as apenadas, mas organizam e regulamentam também os procedimentos para os visitantes.

12 Tchekhov, 1983, p. 25. Fala da personagem Liuba em O jardim das cerejeiras. 
Para entrar, passávamos por revistas, cujo objetivo era coletar qualquer objeto proibido, tais como celulares e objetos cortantes ou que pudessem ser utilizados como arma. Isso exigia de nós uma organização prévia quanto à operacionalidade das ações, já que a cada visita era necessária a autorização para a entrada com equipamento de som, máquina fotográfica e câmera de vídeo. Todos os registros deviam ser feitos sem que os rostos das apenadas aparecessem, como uma forma de proteger sua privacidade.

Entrar em uma penitenciária requer burocracia intensa e muitos acordos prédeterminados entre as instituições e as pessoas envolvidas. Existiu, inclusive, a necessidade de fazer seguro de vida para os integrantes do projeto. Foi feito também, previamente, um Termo de Colaboração entre a Universidade e a Superintendência dos Serviços Penitenciários do Rio Grande do Sul - SUSEPE RS, que tratou amplamente de todas as regras burocráticas para a ação.

Saímos da universidade carregando nossas malas, Tchekhov e o sabor da impermanência da vida. Entramos em um território desconhecido e encontramos mulheres, moças, mães, avós. Assumimos o silêncio e a atenção, numa tentativa de desprendimento do mundo exterior. Ao chegarmos, agentes penitenciários conduziram-nos para um contêiner nos fundos da prisão, uma espécie de celas desocupadas rodeadas de grades: espaço que foi improvisado para servir como nosso camarim. Dentro deste espaço pequeno, havia um beliche com duas camas de concreto, uma pia e um vaso sanitário. Maquiamo-nos frente a uma espécie de adesivo metálico colado na parede, que servia de espelho. Estranho, pois ele revelava uma imagem distorcida de nosso rosto. Imaginamos como seria acordar todos os dias e ver o próprio rosto distorcido. Nosso reflexo no espelho da cadeia nos devolvia um rosto privado de seus contornos.

Com muitas incertezas, nos preparamos para a apresentação e vestimos as personagens de Tchekhov. Será que elas vão gostar da peça? Será que estamos no lugar certo? Será que faremos algum sentido? Em nossos corpos, estavam impressos a curiosidade e, também, o medo. Medo de experimentar um contraste severo entre a proposição do grupo e a recepção das apenadas. No entanto, uma das primeiras falas do nosso espetáculo convidava a uma conotação horizontal 
entre nós e aquele público, uma possibilidade de unidade:

Poderíamos ser uma camponesa apaixonada, um jovem que anseia por mudança. Poderíamos ser comerciantes, burgueses, desempregados, estudantes, artesãs. Poderíamos estar privadas de ver o horizonte. Poderíamos ser um grupo de $\operatorname{artistas}^{13}$.

Mas fomos, como estrangeiras e estrangeiros, adentrando em um lugar desconhecido. Mesmo que o espaço prisional não tenha sido anteriormente aventado como possibilidade para apresentarmos o espetáculo, ao conhecermos o contexto sentimos a emergência de levar o teatro para aquele lugar. Além disso, foi uma possibilidade de confrontarmos o alcance da nossa montagem, que para nós era tão plena de força e sentidos. Para a jornada nas duas penitenciárias, com objetivos mais abrangentes, foi preciso aceitar o desconhecido e, a partir dele, nos lançarmos à experiência, dispostos a nos apropriarmos daquele lugar para fazermos teatro. O espaço da prisão constitui ele mesmo seu próprio território, próximo da definição apresentada por Haesbaert (2007, p. 20):

Território, assim, em qualquer acepção, tem a ver com poder, mas não apenas ao tradicional "poder político". Ele diz respeito tanto ao poder no sentido mais explícito, de dominação, quanto ao poder no sentido mais implícito ou simbólico, de apropriação.

O jardim das cerejeiras, de Tchekhov, invadiu o espaço destinado a punir e vigiar, abrindo uma fresta, uma saída, mesmo que fugaz. Reconhecemos a cadeia como apenas mais um lugar, não como algo estagnado e fixo, mas um espaço a mais para o contágio da arte, para a crítica e para a mudança.

Após organizarmos os adereços cênicos e a cenografia no pátio do presídio, aguardamos ansiosos a chegada das detentas, que logo se sentaram em nossa frente, em bancos e cadeiras devidamente organizados e distribuídos pelo ambiente. Em nós, ecoava um misto de euforia, ansiedade e nervosismo. Começamos o espetáculo, desenhando no chão uma linha com água, para

${ }^{13}$ Prólogo do roteiro do espetáculo O jardim das cerejeiras. 
delimitar o espaço da encenação. A água em poucos minutos evaporou, mas a instauração desse novo território e os sentidos por ele gerados reverberaram por muito tempo.

Os atores entraram correndo, o pátio se transforma em quarto de infância e uma família russa entra na casa. Uma nova dimensão estabelece-se: a da reinvenção, da memória, da cumplicidade, da partilha, da capacidade extraordinária de nos colocarmos no lugar do outro - de imaginarmos, juntas e juntos, um futuro melhor, mesmo dentro de um presente incerto - de nos deixarmos levar pelo jogo, pelas canções, pela transitoriedade da vida, pelo fim da inocência que experimenta a coragem de dizer adeus.

Figura 2 - Horizontes. Colagem manual de Luzia Ainhoren, a partir de fotografias de Rodrigo Waschburger, ambos participantes do projeto. Feita com papel, cola e oil pastel.

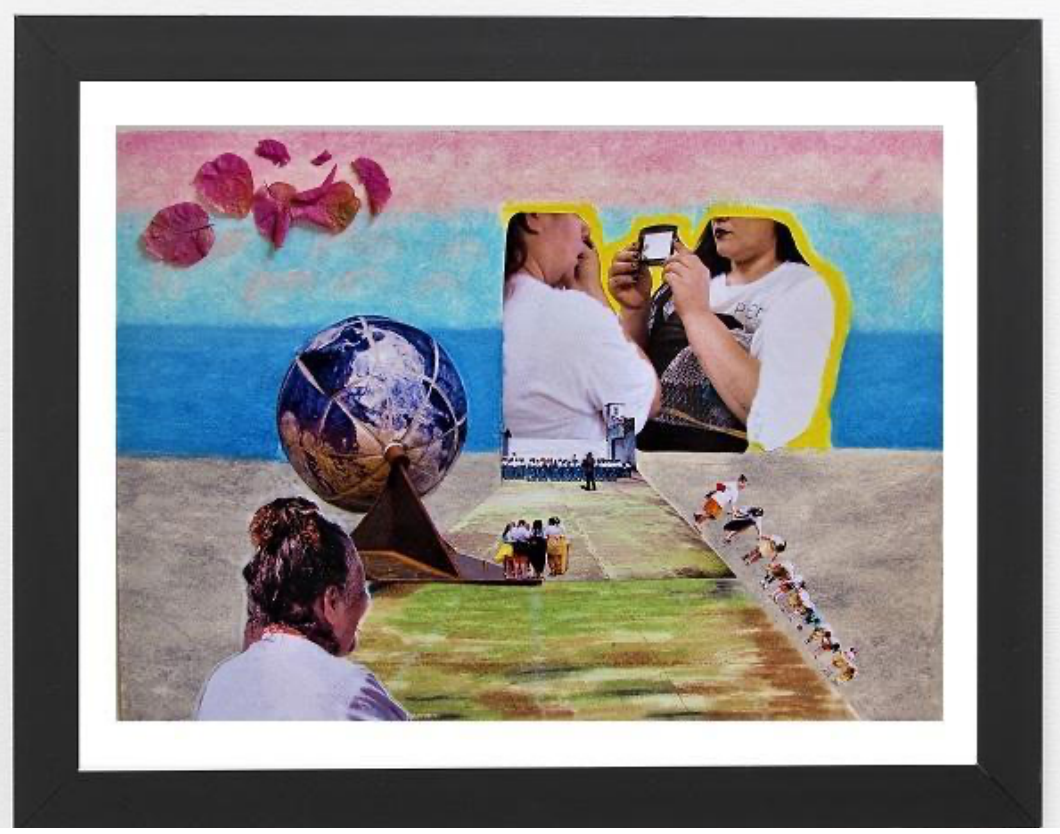

Durante o debate que realizamos logo após uma das apresentações, dissenos uma das apenadas: "Viajei no tempo dentro da cadeia pela primeira vez reclusa em quatro anos. Amei!"14 As memórias também encontravam lugar naquelas

${ }^{14}$ Conforme orientação das assistentes sociais, omitimos os nomes das mulheres como uma forma de preservarmos sua privacidade. Todos os depoimentos das apenadas estão entre aspas no texto. Nesta página os depoimentos foram extraídos de pequenos bilhetes que as apenadas foram convidadas a escrever após a apresentação, com suas impressões sobre a peça. 
mulheres, como é possível perceber em outras duas falas: "Gostei do homem que não deixou vender a casa. Estava muito preocupado com o jardim. Lembrei da minha casa, que deixei sozinha, abandonada, sem ninguém. Obrigada a todos." Outra mulher escreveu: "Foi um momento muito bom, me lembrou como é estar em casa e por alguns motivos ser tirada do nosso conforto. A peça foi ótima!"

Tchekhov nos causa mesmo esse furor de sentimentos e sensações, um misto de alegria e tristeza nos corpos daqueles que atuam e, consequentemente, na plateia, que assistiu atenta a cada detalhe apresentado: "Excelente! A vida continua. Obrigada." Em outros depoimentos: "Fui feliz por alguns minutos e agora sei que existe vida lá fora.", e "Foi lindo! Eu nunca tinha visto."

Para Almeida (2014), o sistema prisional, bem como os presídios, são pouco estudados pela academia e pela sociedade, a falta de conhecimento sobre estes espaços gera "estereótipo sobre as prisões, como se fossem todas iguais e estáticas em suas práticas” (Almeida, 2014, p. 1211). Ações de cunho artístico e educacional são necessárias dentro de espaços que, historicamente, pouco corroboram para a formação de uma sociedade mais justa e agregadora. De outra parte, quando o teatro acontece em um espaço não convencional, ou é apresentado em espaços diferentes do tradicional palco italiano, estabelecem-se outras conexões entre a cena e o público que só são possíveis pelas especificidades de cada lugar. O espaço promove, também, a qualidade do encontro, influencia a fruição do espectador e a própria ação e o jogo das atrizes e atores. Incluir o espaço nos códigos da cena e na participação do público é fundamental para que o evento se estabeleça. É improvável ficar indiferente ao território dotado de signos e significantes de um presídio.

Mas, como essas qualidades semânticas podem afetar a encenação, diz respeito também a uma predisposição ao lugar, uma certa confiança ao próprio poder do teatro como acontecimento, uma disposição em estar abertos a acolher as características próprias que o espaço já sugere, imprimindo novas dinâmicas para o "aqui e agora" da cena. O território do teatro, ao invadir o território da prisão, dilui as delimitações, borra os limites e, por isso mesmo, promove novas ideias. Em certa dimensão, pode-se transformar a carga simbólica de espaços 
disciplinadores e codificados pelo poder em espaços de troca e apreciação artística.

\section{Algumas impressões sobre as oficinas}

Saudades. Sei que serei esquecida: assim é a lei do mundo. Um doce sonho, querida, dura apenas um segundo. ${ }^{15}$

A proposição das oficinas teatrais permitiram-nos uma convivência mais duradoura e profunda com as apenadas. Uma estudante bolsista ${ }^{16}$, em cada uma das penitenciárias, foi responsável por ministrar a oficina, sempre com o acompanhamento da coordenadora do projeto. As oficinas, assim como todo o projeto, contaram também com a colaboração de outros integrantes da equipe de ex-alunos e estudantes da UERGS e a assessoria fundamental das assistentes sociais e da direção dos presídios, bem como o apoio da coordenação responsável na SUSEPE.

No teatro, quando nos lançamos ao vazio de uma improvisação individual ou coletiva, são amplas as possibilidades que se apresentam. Cabe ao atuante escolher um caminho - quer seja um som, um movimento, uma pausa, um olhar, uma lembrança, um impulso - e seguir. Não há previsibilidade sobre o destino dessa escolha, há apenas possibilidades. Gatilhos que geram movimentos e ultrapassam as condições estáticas. Quem sabe um gesto ative uma lembrança esquecida ou a possibilidade de ser algo diferente, faça vibrar um coração que há meses não se manifesta e reacenda paixões? Quem sabe uma pequena fresta tenha sido aberta no cotidiano enclausurado das detentas?

Cada oficina aconteceu em oito encontros, nos quais desenvolveram-se jogos, atividades em grupo e exercícios de improvisação. Cada processo resultou em um material cênico, com temática eleita pelas participantes, as quais abordavam questões sobre a família e de seu cotidiano. Nas palavras de Jean-

15 Texto do material cênico Mãe elaborado pelas apenadas da Penitenciária Modulada de Montenegro.

${ }^{16}$ Camila Pasa foi responsável pela oficina em Montenegro e Rafaela Giacomelli, em Torres. 
Pierre Ryngaert, "as práticas de improvisação absorvem como uma esponja a realidade imediata e constroem um referente a partir da experiência instantânea dos jogadores e de sua percepção da situação.” (Ryngaert, 2009, p. 199).

Em Montenegro, a temática definida por elas foi maternidade e a figura da mãe, e o processo resultou na criação de uma montagem, permeada por humor e afeto, sobre as relações entre mães e filhas. Em Torres, o trabalho foi desenvolvido a partir do Teatro Imagem, de Augusto Boal, e resultou em um mosaico de imagens cênicas que traçaram paralelos entre o cotidiano de abusos e de violências que aquelas mulheres já haviam vivenciado, em contraste com outras cenas que apresentavam soluções não violentas.

Pensar o território do presídio também é entender que a resistência permeia cotidianamente os dias das mulheres enclausuradas. Foi nessa resistência que o teatro encontrou parceria. O teatro experimentado na prisão promoveu a desestabilização do dia, de uma rotina específica vivida pelas apenadas, que tinham que seguir em fila, de braços cruzados e olhos baixos para a cela, para o pátio ou até para a aula de teatro, mas que, ao adentrar no âmbito da oficina, estabelecia-se um convite oposto: levantar os olhos, soltar os braços, exercitar a própria voz, exercitar a escuta e, até mesmo, em certos casos, sobrepujar o torpor provocado pelos remédios. São ações sutis que propõem uma inversão naquele jogo de forças do território prisional.

Diante das apenadas, presenciávamos pequenos levantes pessoais vividos em grupo. Nos momentos do teatro, os caminhos eram de desordem, de uma certa dissolução do status quo premeditado. Configuraram-se infinitas rotas de fuga individual ou coletiva em direção a novos saberes, a percepções diferenciadas, a atitudes imprevisíveis do corpo e dos jogos, que atiçaram e promoveram novas relações e ideias sobre si mesmas e o mundo, para além daquelas que estavam sendo impostas ou que já eram conhecidas por elas. Nesse encontro e nesse embate entre o que estava já estabelecido naquele espaço e o que estava surgindo como força nova através do teatro, provocava-se uma inversão de fluxo, uma linha de fuga, uma desterritorialização. Ao refletirmos sobre a experiência vivenciada no presídio e identificarmos o impacto dessa ação em nossa formação artística e 
pedagógica, é justamente este aspecto que ilumina nossas questões iniciais ao realizarmos este relato de experiência: a capacidade de resistência daquelas mulheres nutria e reacendia nossa própria capacidade de resistir.

Mas, para que serve mesmo uma cadeia? Esse sistema tem apresentado resultados efetivos para a sociedade? Essas perguntas ecoavam em nossas cabeças. Segundo Santos (2007), podemos entender a sobrevivência em determinados contextos territoriais, como observamos no caso do presídio, a partir do paradoxo: "obedecer para subsistir e resistir para poder pensar o futuro. Então a existência é produtora de sua própria pedagogia” (Santos, 2007, p. 57). Resistir ao cárcere. Resistir às restrições impostas pela sociedade. Resistir ao sistema que criminaliza, com maior contundência, a partir da política de guerra às drogas, àquelas que se encontram em uma posição subalterna e vulnerável, como nos aponta Juliana Borges:

No caso das mulheres é muito comum o relato de buscas e "apreensões" e invasões sem mandado de busca em seus domicílios; tortura e humilhação para obter informações das quais sequer elas têm conhecimento; relatos de prisão pela proximidade com algum familiar envolvido com o tráfico; prisões quando transportando pequenas quantidades, sendo que muitas são intimidadas a fazer isso. A imensa maioria dessas mulheres é ré primária, ou seja, jamais teve passagem pelos registros policiais e, quando estabelecem algum tipo de relação com o tráfico, esse processo se dá na base da cadeia econômica do tráfico, ao que conclui a advogada e pesquisadora Luciana Boiteux que suas prisões não têm nenhum impacto na dinâmica e no funcionamento da economia das drogas (Borges, 2019, p. 106-107).

Mesmo dentro do cárcere, podíamos perceber, entre as apenadas, uma força, a vontade de aprenderem consigo mesmas e com as oportunidades que eventualmente chegavam de fora das penitenciárias, convidando-as a pensar em outras possibilidades para suas existências. Percebemos que, ao se estabelecerem as dinâmicas intrínsecas do fazer teatral entre aquelas mulheres, surgia uma possibilidade renovada de contato consigo mesmas e com o mundo, através da relação afetuosa, do prazer, da conversa, da solidariedade, do encorajamento, da energia, da presença, do contato, da memória, de um senso coletivo e estético na solução de problemas e no estímulo ao pensamento crítico diante de si e da 
realidade.

O teatro ressignificou as lembranças que tinham do outro lado do muro. Um corpo em movimento que formava imagens, a voz que entoava novas palavras imprevisíveis, talvez até inventadas por outros, experiências e significados que povoavam o corpo e a memória. Um exercício de alteridade que pode transformar corpos.

$\mathrm{Na}$ conclusão das oficinas, vimos mulheres exercitando a alteridade e modificando papéis, vivenciando mães, irmãs, amigas e namoradas das histórias de vida umas das outras. Nesse sentido, foi-nos perceptível que:

Por sua ancoragem na afetividade, a improvisação não nega qualquer conduta racional, mas estimula, no contexto de uma formação, a tomar consciência do papel do inconsciente e do sensível na relação do indivíduo com o mundo. (Ryngaert, 2009, p. 97).

Adentrar uma experiência já conhecida com a roupagem de uma outra persona pode servir para um deslocamento de olhar acerca de experiências pessoais, de traumas e de memórias dolorosas. Isso pudemos observar através dos depoimentos de algumas participantes:

Eu chorava muito. Eu tô reagindo. Elas me chamam de China Véia, sempre chorando. Eu tô reagindo, eu tô conseguindo falar. Eu guardava pra dentro e chorava. Agora eu falo o que eu tenho que falar.

Eu já falava antes, agora falo mais ainda. Em compensação, depois do teatro me deu uma baita dor abdominal de tanto rir.

Me tirou um pouco a minha vergonha, mas eu ainda tenho um pouco de vergonha.

Ao serem indagadas se descobriram alguma coisa diferente depois dessa experiência, uma delas disse:

De falar, olha, eu acho que eu piorei. Eu já era agitada, fiquei mais agitada ainda.

Quando perguntamos se viu algo em si que, antes da experiência com o teatro, não conhecia. Destacamos duas respostas: 
Coragem! Porque nem no colégio eu tinha coragem. Sabe aquelas crianças que tu tem que segurar o cartaz, eu era a que segurava o cartaz (gesto de segurar o cartaz na frente do rosto) e ficava que nem um poste. Agora, né? (gesto de desinibição).

Ah, elas também quiseram desistir, né? Foi uma briga pra fazer elas ficar (sic).

Ao atuarem em frente a suas colegas, aos guardas armados, às representantes da instituição e a alguns de nós, foi possível reconhecer a possibilidade de sonhar, de acessar diferentes pontos de vista na reinvenção de outras narrativas do possível e, nisso, a autoafirmação de uma qualidade antes impensada. Na finalização do projeto, foi realizado um debate com as mulheres encarceradas, as assistentes sociais e a coordenação do departamento educacional da SUSEPE. Deixamos aqui, transcrições do registro em vídeo deste debate, apresentando algumas das vozes das participantes:

Parecia que a gente estava num sonho. Um sonho que foi realizado.

Foi uma sensação, assim, sem explicação. Parece que tirou um peso de dentro de nós. Nós nos soltemo (sic) e mostremo (sic)... nossa... nós somos capazes de fazer isso.

Figura 3 - Rosa. Colagem manual de Luzia Ainhoren, a partir de fotografias de Rodrigo Waschburger, ambos participantes do projeto. Feita com papel, cola e oil pastel

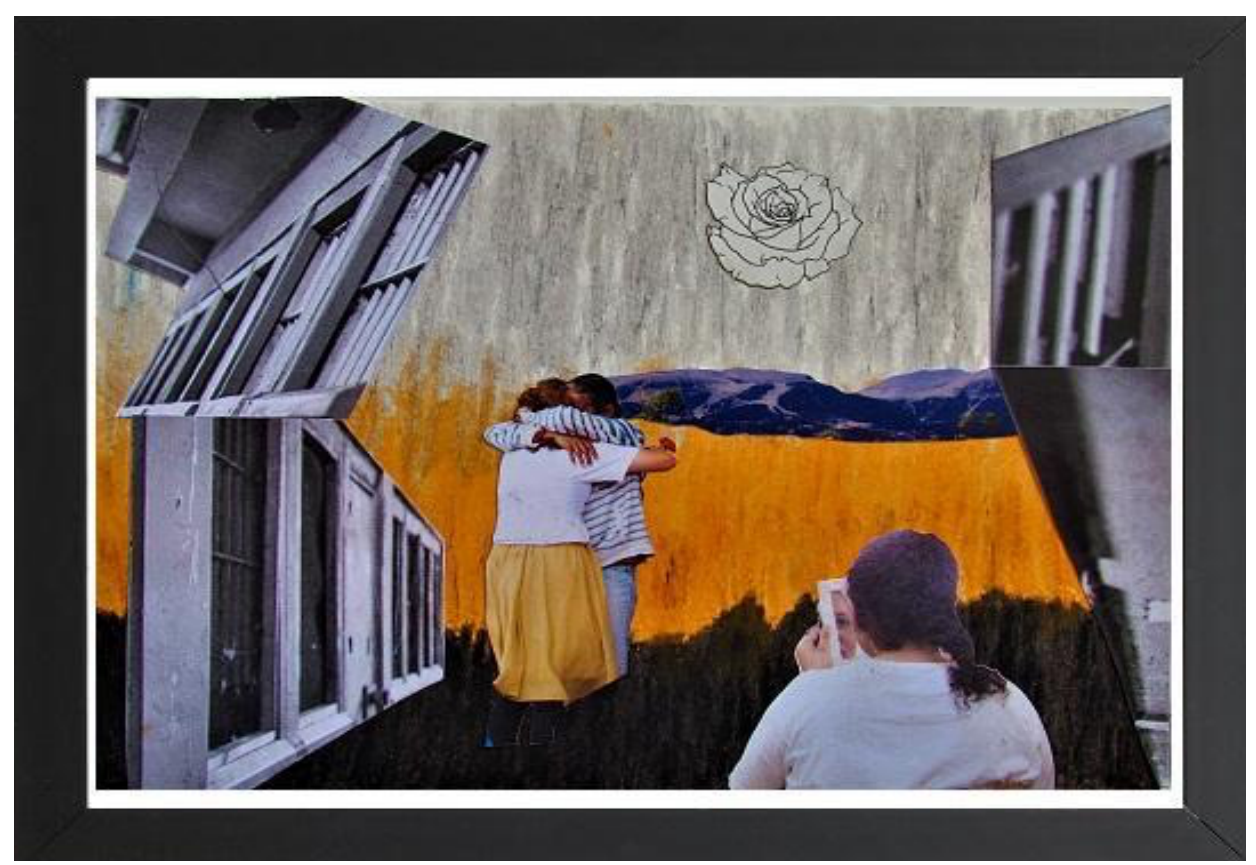




\section{Efeitos delas em nós e vice-versa: um fim ou um novo começo}

Vamos, vamos embora daqui meu amor; nós plantaremos um outro jardim mais bonito do que esse; você vai ver se não. ${ }^{17}$

Voltando às questões iniciais, percebemos que nossa experiência artística dentro do cárcere foi uma passagem, um encontro fugaz no tempo, mas tão veemente como aquela pequena chama que pode queimar muito. Um gesto tênue, que não sabíamos ao certo onde nos levaria, mas constantemente alimentado pela experiência e pela confiança no teatro. Experimentamos o fazer teatral como a emergência de um território apto à transformação do mundo e de nós mesmos. Um movimento que convidou a acendermos algumas luzes, mesmo que bruxuleantes, sobre os problemas enfrentados pelas mulheres em condição de cárcere, a nossa forma de resistência ao apagamento e ao esquecimento da mulher nessa condição e nossa contribuição para o exercício constante de empoderamento, tanto delas quanto de nós mesmos.

Essa ação promoveu o exercício da autonomia do próprio processo formativo e criativo. Foi fundamental o exercício artístico, pedagógico e de produção de um projeto tão complexo. Uma experiência marcante dentro da formação acadêmica, tanto que, mesmo depois de já estarmos graduados, os estudantes que participaram da ação continuamos produzindo frutos sobre aquela experiência. Foram determinantes a sensibilização e a capacitação individual para a configuração da experiência coletiva ou, até mesmo, da própria liberdade de escolha dos espaços onde o teatro pode acontecer, dentro de nossas perspectivas pedagógicas e artísticas.

Para as apenadas, esperamos que tenham experimentado a si mesmas como possíveis agentes transformadores de sua história e de seu contexto. Nós, enquanto professores e artistas que visitaram o cárcere, tivemos muitas evidências desse comprometimento. Claro que nem tudo foram pérolas, tivemos

17 Tchekhov, 1983, p. 61. Fala da personagem Ânia em O jardim das cerejeiras. 
muitas dificuldades em relação a muitos aspectos na viabilidade do projeto, sobretudo no que tange à burocracia exigida entre as duas instituições, UERGS e SUSEPE, mas não foi isso o que ficou mais forte em nossas memórias.

O que se eleva dessa experiência são, sobretudo, essas suspensões de vida, de Tchekhov e das mulheres presas, que nos surpreendiam por suas sincronias. As histórias das personagens da ficção e da realidade, inclusive nossas, atravessando-se em choro, em riso, em perda, em conformação e em revolta, mas sobretudo em estupor diante dos acontecimentos imprevisíveis da vida. Brook comenta sobre os personagens de O jardim das cerejeiras de Tchekhov:

Seu drama é que a sociedade - o mundo externo - bloqueia suas energias. A complexidade de seu comportamento não está indicada por palavras, mas emerge da construção de um mosaico constituído de um número infinito de detalhes. É essencial compreender que não se trata de peças que giram em torno de pessoas letárgicas. São pessoas hipervivazes situadas num mundo letárgico, forçadas a dramatizar os mínimos acontecimentos em função de um apaixonado desejo de viver. Não desistiram. (Brook, 1995, p. 214).

Não desistimos. Na intersecção dos territórios do teatro e do presídio, criamos uma efeméride espaço temporal que segue viva ainda em nossa memória. Intentamos, de algum modo, seguir Tchekhov e aquelas mulheres, que nos guiaram na presentificação de outras formas para nossa condição humana - tão misteriosa quanto passível de mudança - para além de muros, sejam eles de concreto ou de sensações, sempre jogando com a impermanência libertadora do tempo e do espaço que o teatro é capaz de proporcionar. Apesar das dificuldades e dos momentos de desistência, ao concluírem sua apresentação, as participantes das oficinas estavam orgulhosas por não desistirem e por se apoiarem, por não deixarem as companheiras desistirem também.

A experiência do teatro dentro do presídio mostra que essas pessoas consideradas indesejáveis, depositadas dentro do cárcere, portam uma riqueza criativa e sensível, potência de vida e imaginação, que carecem de espaço para expressão, para escuta e para transformação. Enquanto o sistema carcerário existir, dentro do sistema econômico e social que vivemos, pensamos que o teatro 
possa ser uma brecha, um respiro, um impulso para que, paralelamente às transformações das condições materiais da existência, possamos algum dia efetivamente abolir essa instituição tão obsoleta, que serve apenas para reproduzir desigualdades, violentar e sufocar vidas, especialmente vidas jovens, pretas e pobres.

Encerramos com uma bela reflexão de uma das mulheres encarceradas, que atinge precisamente o sentido dos textos de Tchekhov para nós: "Eu adorei o que foi feito, pois tudo que fizemos no passado, passou, pois temos de viver o presente e reconhecer que podemos fazer nossa própria história para uma vida melhor.”

\section{Referências}

ALMEIDA, Guilherme Rosa de. Território e cotidiano da prisão: estudo de caso do centro de ressocialização de Cuiabá/MT. Anais do / Congresso Brasileiro de Geografia Política, Geopolítica e Gestão de Território, 2014, Rio de Janeiro. Porto Alegre: Editora Letra1; Rio de Janeiro: REBRAGEO, 2014, p. 1210-1220.

BORGES, Juliana. Encarceramento em massa. São Paulo: Sueli Carneiro; Pólen, 2019.

BROOK, Peter. O ponto de mudança: quarenta anos de experiências teatrais. Rio de Janeiro: Civilização Brasileira, 1995.

DAVIS, Angela. Estarão as prisões obsoletas? Rio de Janeiro: Difel, 2019.

HAESBAERT, Rogério. Território e multiterritorialidade: um debate. Universidade Federal Fluminense. GEOgraphia, Ano IX, No 17, 2007.

PLÁCIDO, Vera Lúcia S. SANTOS, L.H.C. A importância da cartografia social para a compreensão do território da arte: o exemplo do grupo Savuru, Campinas/SP. Geographia Opportune Tempore, Universidade Estadual de Londrina, vol. 5, n. 1, p 153-166, 2019. Disponível em:

http://www.uel.br/revistas/uel/index.php/Geographia/article/view/37224/26293 Acesso em: 27 jul. 2020

RYNGAERT, Jean Pierre. Jogar, representar: práticas dramáticas e formação. São Paulo: Cosanaify, 2009.

SANTOS, M. Por uma outra globalização: do pensamento único à consciência universal. Rio de Janeiro: Record, 2006. 
SIGILLÓ, Giovanna Penhalbell. Mulheres aprisionadas: uma história do patriarcado. OutrasMídias/Justificando, 7 de novembro de 2019. Disponível em: https://outraspalavras.net/outrasmidias/mulheres-aprisionadas-uma-historia-dopatriarcado/ Acesso em: 08 ago. 2020

TCHEKHOV, Anton. O jardim das cerejeiras. Tradução de Millôr Fernandes. Porto Alegre: L\&PM Editores Ltda, 1983.

TCHEKHOV, Anton. O jardim das cerejeiras. Tradução de Jorge Maricato. 2013. Disponível em:

https://edisciplinas.usp.br/pluginfile.php/4505454/mod resource/content/2/0\%2 OJARDIM\%20DAS\%20CEREJEIRAS.pdf Acesso em: 27 jun. 2020.

Recebido em: 14/10/2020

Aprovado em: 29/11/2020 